\title{
CORRELATION BETWEEN ADENOSINE DEAMINASE ACTIVITY IN PLEURAL FLUID AND SERUM OF PATIENTS WITH PLEURAL EFFUSION
}

\author{
Pande Putu Ayu Patria Dewi ${ }^{1}$, Aryati ${ }^{1}$, Leonita Anniwati ${ }^{1}$, Isnin Anang Marhana ${ }^{2}$ \\ ${ }^{1}$ Department of Clinical Pathology, Faculty of Medicine Airlangga University/Dr. Soetomo Hospital, Surabaya, Indonesia. E-mail: patriadewi@gmail.com² \\ Department of Pulmonology and Respiratory Medicine, Faculty of Medicine Airlangga University/Dr. Soetomo Hospital, Surabaya, Indonesia
}

\begin{abstract}
Pleural effusion is an abnormal accumulation of fluid in the pleural space resulting from increased production of fluid or decreased resorption of fluid in the pleural space. Pleural effusion can be caused by infectious diseases, malignancies, collagen disease, gastrointestinal disease, heart disease and other causes such as medication. Adenosine Deaminase (ADA) is an enzyme involved in the catabolism of purines. This enzyme can be measured in pleural fluid, serum and other body fluids such as cerebrospinal and ascites fluid. The aim of this study was to analyze the correlation between adenosine deaminase activity in pleural fluid and serum in patients with pleural effusion. This research was an observational study with a cross-sectional design. Examination of ADA activity was performed in pleural fluid and serum. Adenosine deaminase activity was examined using photometric methods (Non-Giusti), using Diazyme reagent by TMS 24i Premium. Subjects were 46 patients with pleural effusion caused by malignancies, tuberculosis and systemic diseases. Mean \pm SD ADA activity for all pleural effusion samples in serum was $13.037 \pm 8.365$ (0.5-34.1) $\mathrm{U} / / \mathrm{L}$ and pleural fluid $30.843 \pm 28.860$ $U / / L$ (1.3-140.8). No correlation between ADA activity in serum and pleural fluid $(r=0.173, p=0.252)$ was found in all samples. No correlation between ADA activity in serum and pleural fluis was found in malignancies $(r=0.109, p=0.630)$, tuberculosis $(r=0.366, p=0.123)$, systemic diseases $(r=0.466, p=0.429)$ and nontuberculosis group ( $r=0.126, p=0.532)$. There was no correlation between pleural fluid ADA activity and serum.
\end{abstract}

Key words: Adenosine deaminase, pleural fluid, serum, correlation

\section{INTRODUCTION}

Pleural effusion is an abnormal accumulation of fluid in the pleural space resulting from increase production of fluid or decrease resorption of fluid in the pleural space..$^{1-3}$ Pleural effusion can be caused by infectious diseases, malignancies, collagen disease, gastrointestinal disease, heart disease and other causes such as medication, nephrotic syndrome and radiation. ${ }^{3}$ In developing countries the most common causes of pleural effusion are tuberculosis, pneumonia and malignancies whereas in developed countries such as United States and Britain malignancies are more prevalent. Annual incidence in the United States for pleural effusion caused by malignancies was estimated as 250,000 in a year. ${ }^{4}$

Adenosine deaminase (ADA) is an enzyme involved in the catabolism of purines which catalysis the change of adenosine into inosine and deoxyadenosine into deoxyinosine. In humans it spreads throughout the body but its physiological role is especially important in the lymphoid tissue. ${ }^{5}$

ADA activity has been used to support the diagnosis of tuberculosis because the examination does not take a longer time, is cheap and has a high sensitivity and specificity. ${ }^{4}$ A meta-analysis study from 63 researchers found that the diagnostic value of ADA in endemic areas tuberculosis was very high with a sensitivity of $92 \%$ and a specificity of $90 \%$. Adenosine deaminase can be measured by two methods which are Giusti Galanti method and Non-Giusti method. Principles of both methods are photometric. ${ }^{4-6}$

Adenosine deaminase can be measured in pleural fluid, serum and other body fluids such as cerebrospinal and ascites fluid. Increased serum ADA activity has been demonstrated in several diseases such as tuberculosis, typhoid fever, infectious mononucleosis, liver diseases, sarcoidosis, pneumonia and malignancies. ${ }^{5,66}$ A research showed that in restricted resource areas, serum ADA activity with a high specificity might 
be useful as an alternative test to rule out the diagnosis of tuberculosis. ${ }^{7}$

Adenosine deaminase research activity in recent years is focused on pleural fluid. Serum ADA activity is more easily examined compared to pleural fluid, but recent research only focused on serum or pleural fluid.

The aimed of this study was to analyze the correlation between adenosine deaminase activity in pleural fluid and serum in patients with pleural effusion.

\section{METHODS}

The Ethics Committee Institute of the Dr. Soetomo Hospital Surabaya approved the protocol and written informed consent was obtained from all patients. This research was an observational study with a cross-sectional design and conducted in the Outpatient Clinic and Pulmonary Ward, Dr. Soetomo Hospital, Surabaya and a laboratory in Surabaya during August-November 2016.

Population in this research were patients with pleural effusion in the Outpatient Clinic and Pulmonary Ward, Dr. Soetomo Hospital, Surabaya during AugustNovember 2016. Samples in this study were a part of the population fulfilling the inclusion and exclusion criteria. The inclusion criteria were males or females over 18 years-old, physical examination and other examination showing pleural effusion, signing informed performed using Pearson because the distribution of samples was normal. systemic diseases $(n=5)$. The demographic and clinical characteristics of the patients can be seen Table 1. Mean \pm SD ADA activity in pleural fluid for all samples was $30.843 \pm 28.860 \mathrm{U} / /$ $\mathrm{L}$ and in serum was $13.037 \pm 8.365 \mathrm{U} / / \mathrm{L}$. The data for

Table 1. Characteristics of patients with pleural effusion at the Dr. Soetomo Hospital during August-November 2016

\begin{tabular}{|c|c|c|}
\hline Variable & $\mathbf{N}$ & $\%$ \\
\hline \multicolumn{3}{|l|}{ Gender } \\
\hline Males & 26 & 56.5 \\
\hline Females & 20 & 43.5 \\
\hline Age Mean $\pm S D$ & \multicolumn{2}{|c|}{$47.37 \pm 13.582$} \\
\hline \multicolumn{3}{|l|}{ Disease } \\
\hline Malignancies & 22 & 47.8 \\
\hline Tuberculosis & 9 & 41.3 \\
\hline $\begin{array}{l}\text { Systemic } \\
\text { diseases }\end{array}$ & 5 & 10.9 \\
\hline
\end{tabular}

all subjects and each disease can be seen in Table 2 .

Statistics analysis showed that there was no correlation between ADA activity in serum and pleural fluid $(r=0.173, p=0.252)$ in all samples. Scatterplot correlation between ADA activity in serum and pleural fluid in all samples is shown in Figure 1.

Table 2. ADA Activity in pleural fluid and serum in patients with pleural effusion at the Dr. Soetomo Hospital during AugustNovember 2016

\begin{tabular}{|c|c|c|c|c|c|}
\hline \multirow[t]{2}{*}{ Variable } & \multirow{2}{*}{$\begin{array}{c}\text { All Samples }(n=46) \\
U / / L\end{array}$} & Malignacies & Tuberculosis & Systemic disease & \multirow{2}{*}{$\begin{array}{c}\text { Group Non- } \\
\text { tuberculosis }(n=27) \\
U / L\end{array}$} \\
\hline & & $(n=22) \quad U / / L$ & $(n=19) \quad U / / L$ & $(n=5) \quad U / / L$ & \\
\hline $\begin{array}{l}\text { ADA activity } \\
\text { in serum }\end{array}$ & $\begin{array}{l}13.037 \pm 8.365 \\
(0.5-34.1)\end{array}$ & $\begin{array}{l}11.390 \pm 8.506(1.7 \\
-41.1)\end{array}$ & $\begin{array}{l}12.836 \pm 6.161 \\
(0.5-24.70)\end{array}$ & $\begin{array}{l}21.040 \pm 11.894 \\
(7.90-34.1)\end{array}$ & $\begin{array}{l}13.177 \pm 9.736 \\
(1.7-41.1)\end{array}$ \\
\hline $\begin{array}{l}\text { ADA activity } \\
\text { in pleural flu- } \\
\text { id }\end{array}$ & $\begin{array}{l}30.843 \pm 28.860 \\
(1.3-140.8)\end{array}$ & $\begin{array}{l}20.404 \pm 8.506 \\
(1.30-90.9)\end{array}$ & $\begin{array}{l}46.178 \pm 33.522 \\
(3.90-140.80)\end{array}$ & $\begin{array}{l}18.500 \pm 12.954 \\
(4.60-37.7)\end{array}$ & $\begin{array}{l}20.051 \pm 19.255 \\
(1.3-140.8)\end{array}$ \\
\hline
\end{tabular}

consent. The exclusion criteria were patients with a hemostasis abnormality.

Examination of ADA activity was performed in pleural fluid and serum. Pleural fluid and blood without anticoagulant were centrifugated at 3,000 rpm for 15 minutes and serum and supernatant pleural fluid were obtained. Aliquots of the pleural fluid supernatants and serum were stored at $-80^{\circ} \mathrm{C}$. Adenosine deaminase activity was examined using photometric methods (Non-Giusti) and Diazyme reagent with TMS 24i Premium. Quality control of ADA examination used Diazyme ADA control. Results were
No correlation was found in malignancies $(r=0.109, p=0.630)$, tuberculosis $(r=0.366, p=0.123)$, systemic diseases ( $r=0.466, p=0.429)$ and nontuberculosis group $(r=0.126, p=0.532)$. Scatterplot correlation between ADA activity in serum and pleural fluid in malignacies, tuberculosis and systemic diseases can be seen in Figure 2, 3, 4 and Figure 5.

The proportion of males in this study was higher than females. A study conducted by Verma ${ }^{8}$, found the same results. These results might be associated with the etiology of pleural effusion where 
found the same results. These results might be associated with the etiology of pleural effusion where males contribute more in tuberculosis and lung tumors while females contribute in breast cancer and reproduction cancer. $^{8-10}$

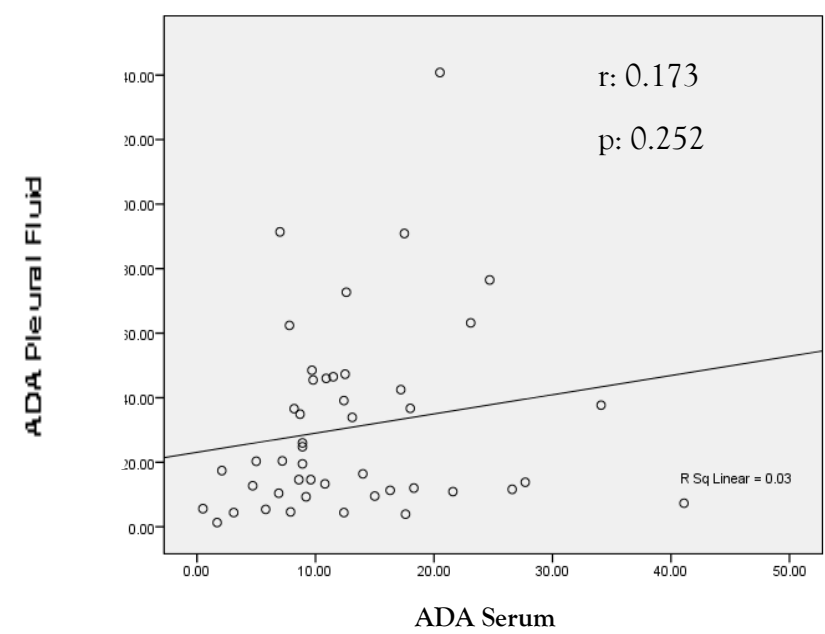

Figure 1. Correlation between ADA activity in serum and pleural fluid $(r=0.173, p=0.252)$ in all samples

Malignancies were the most common etiology in this study. This result was the same as a study by Kusuma in Surabaya, but, Bhoumik in India found that the most common etiology of pleural effusion was tuberculosis. Indonesia is an endemic area of tuberculosis but, this study was cross-sectional so it could not describe the true proportion of etiology pleural effusion. ${ }^{9,11}$

Mean ADA activity in pleural fluid was higher than serum. ${ }^{12}$ Adenosine deaminase is an indicator of cellular immunity in the pleural space primarily by $T$ lymphocytes and macrophages. This enzyme acts in proliferation and differentiation of lymphocytes. Adenosine deaminase activity is ten times higher in lymphocytes than erythrocytes. It also acts in the maturation of monocytes becoming macrophages. ${ }^{5.13}$ Mean ADA activity in pleural fluid higher than serum may be caused by cellular immunity in production and recirculation enzyme between pleural fluid and serum. The number of lymphocytes in pleural fluid also have an impact in the activity ADA.

No correlation between ADA activity in serum and pleural fluid was found in all samples. This result may be caused by a higher interval in ADA activity in pleural fluid and serum and there was a variation of pleural effusion diagnosis. Previous studies rarely reported a correlation between ADA activity in serum and pleural fluid. Urunsak, in Turkey, found a significant correlation between ADA activity in serum and peritoneal fluid in ovarium tumors. ${ }^{14}$

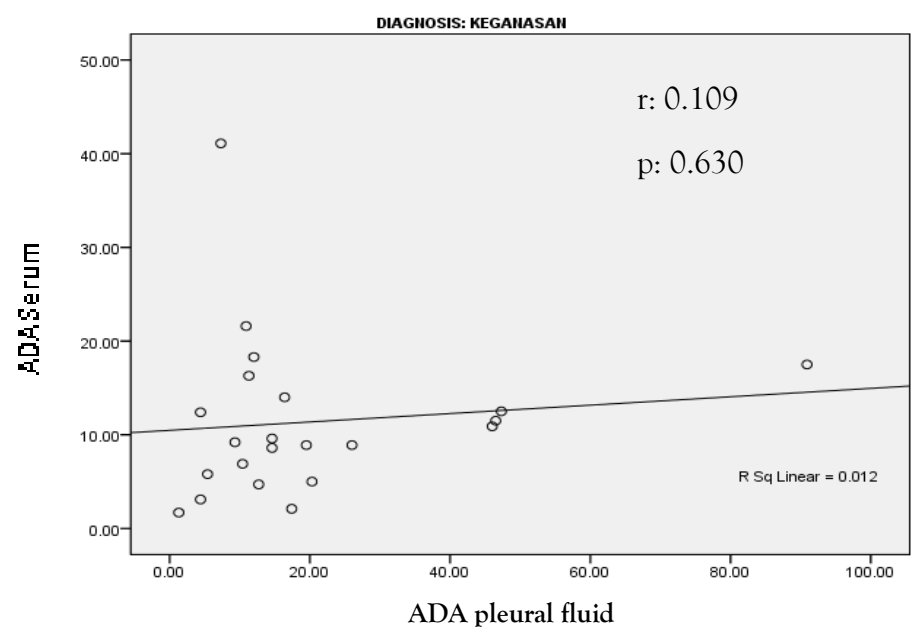

Figure 2. Correlation between $A D A$ activity in serum and pleural fluid $(r=0.109, p=0.630)$ in malignacies

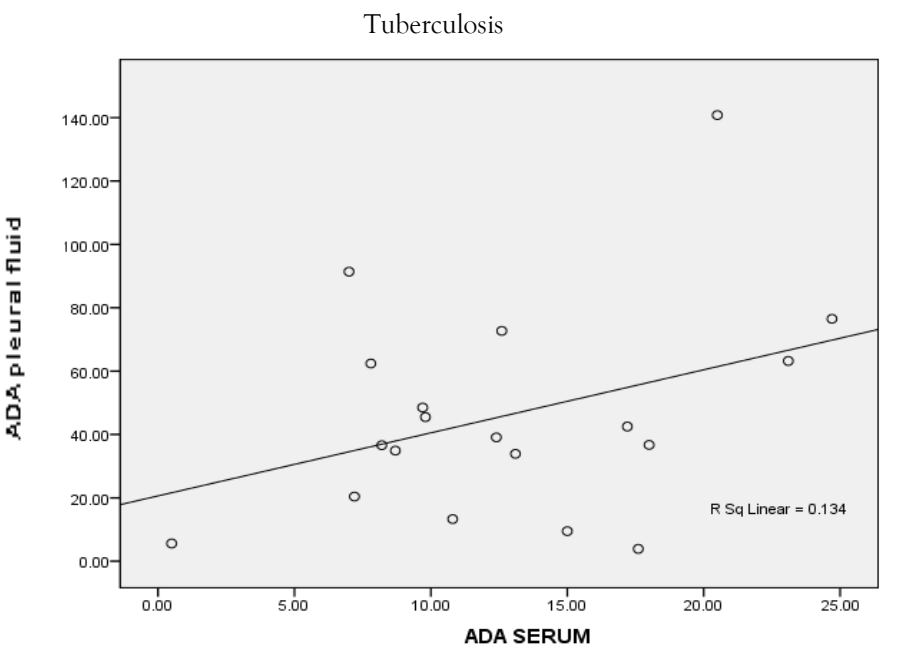

Figure 3. Correlation between $A D A$ activity in serum and pleural fluid $(r=0.366, p=0.123$ ) in tuberculosis

No correlation between ADA activity in serum and pleural fluid was found in all samples. This result may be caused by a higher interval in ADA activity in pleural fluid and serum and there was a variation of pleural effusion diagnosis. Previous studies rarely reported a correlation between ADA activity in serum and pleural fluid. Urunsak, in Turkey, found a significant correlation between ADA activity in serum and peritoneal fluid in ovarium tumors. ${ }^{14}$

No correlation between ADA activity in serum 
and pleural fluid found in malignancies may be caused by variation in the diagnosis of malignancies and carcinogenesis processes. High ADA activity plays an important role in the salvage pathway. Increased ADA activity may be a compensatory mechanism against a toxic accumulation of adenosine. Possible sources of adenosine in tumor cells were cell death, purine metabolism, pyrimidine metabolism, ischemia, AMP release, hydrolysis of $S$ -adenosylhomocysteine and ATP breakdown. ${ }^{15,16}$

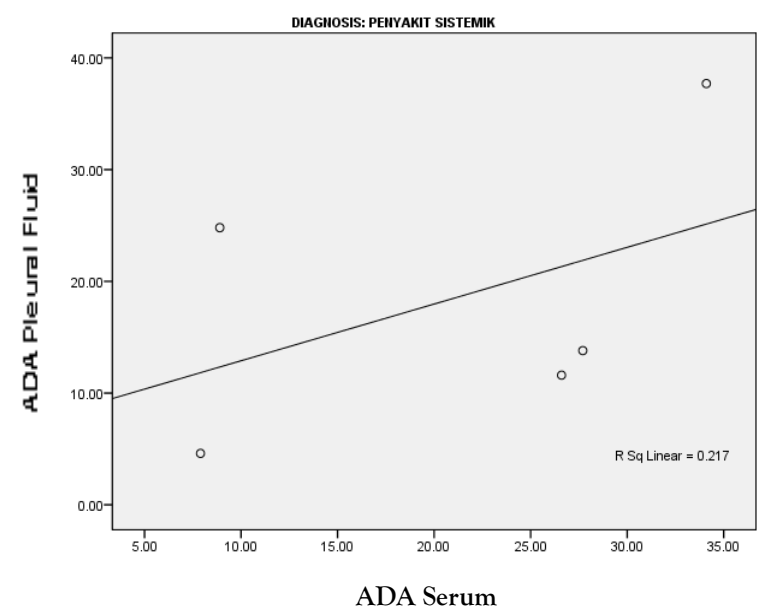

Figure 4. Correlation between ADA activity in serum and pleural fluid $(r=0.466, p=$ 0.429 ) in systemic diseases

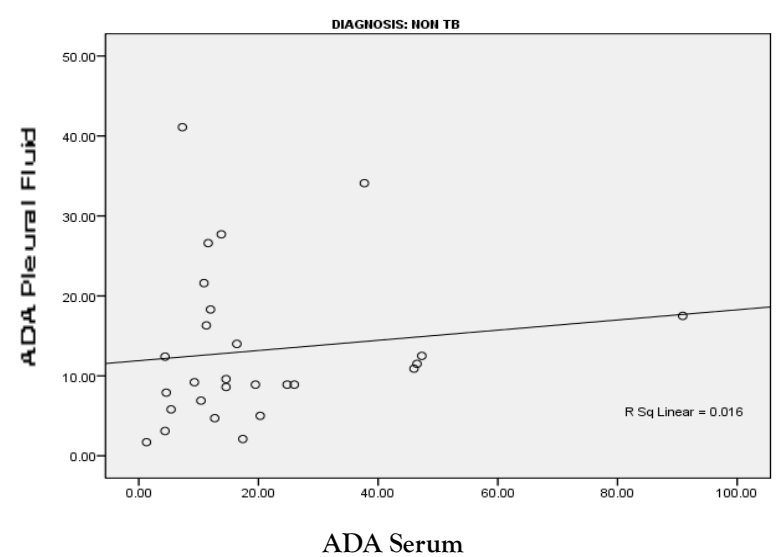

Figure 5. Correlation between ADA activity in serum and pleural fluid $(r=0.126, p=0.532)$ in the nontuberculosis group

No correlation between ADA activity in serum and pleural fluid was found in tuberculosis. This result was hard to explain but, may be caused by a wide interval interindividual in tuberculosis. The lowest value of ADA activity $(0.5 \mathrm{U} / \mathrm{L})$ and highest value of ADA activity (140.8 U/L) was found in in tuberculosis patients.

No correlation between ADA activity in serum and pleural fluid was found in systemic diseases which may be caused by small samples which were obtained in this study with a different diagnosis and spread value of ADA activity. No correlation between ADA activity in serum and pleural fluid was found in the nontuberculosis group which could be caused by variation of diagnosis and dominated by malignancies with different values of ADA activity.

\section{CONCLUSION AND SUGGESTION}

No correlation between ADA activity in pleural fluid and serum in all samples was found. ADA activity in serum cannot yet replace ADA activity in pleural fluid to diagnose the etiology of pleural effusion. A further research requiring more samples of each disease for the diagnostic value activity of ADA serum and pleural fluid and more extended time period is needed.

\section{ACKNOWLEDGEMENTS}

The authors acknowledge the reagent Diazyme support of the PT Nelta, Multi Gracia.

\section{REFERENCES}

1. Hooper C, Lee YC, Maskell N. Investigation of a unilateral pleural effusion in adults: British Thoracic Society pleural disease guideline 2010. In: Thorax, 2010; 65(2): 4- 17.

2. Sato T. Differential Diagnosis of Pleural Effusion. In: JMAJ, 2006; 49(9): 315-19.

3. Khan FY, Alsamawi M, Yasin M, Ibrahim AS, Hamza M, et al. Etiology of pleural effusion among adults in the State of Qatar: a 1-year hospital-based study. In: EMHJ, 2011; 17(7): 611-18.

4. Najib MR. Local anesthetic thoracoscopy: British Thoracic Society pleural disease guideline 2010. In: Thorax, 2010; 65(2):54-i60.

5. Barua $\mathrm{R}$, Hossain M. Adenosine Deaminase in Diagnosis of Tuberculosis: A Review. In: AKMMC Journal, 2014; 5 (2): 43-48.

6. Liang QL, Shin HZ,Wang K, Qin Sm, et al. Diagnostic accuracy of adenosine deaminase in tuberculous pleurisy: A meta-analysis. In: Respiratory Medicine, 2008;102:744 -754 .

7. Salmanzadeh S, Tavakkol H, Bavieh K, Alavi S.M., 2015. Diagnostic Value of Serum Adenosine Deaminase (ADA) Level for Pulmonary Tuberculosis. In: Jundishapur J Microbiol, 2015; 8(3): 2-5.

8. Verma S. Role of pleural fluid adenosine deaminase in aetiological diagnosis of pleural effusion. In: The Internet Journal of Infectious Diseases, 2008; 7(1): 1-4.

9. Kusuma C, Anniwati L, Pradjoko, I. Korelasi antara Aktivi- 
tas Adenosine Deaminase dan Hasil Analisis Cairan Pleura pada Penderita Curiga Efusi Pleura Tuberkulosis. Surabaya, Universitas Airlangga. 2015; 6-63.

10. Ogunleye EO. Aetiology and Demographic Attributes of Common Pleural Collections in an African Population. In: Surgical Science, 2013; 4: 332-34.

11. Bhoumik SK.Evaluation of Adenosine Deaminase (ADA) Activity for Diagnosis of Tubercular Pleural Effusion. In: Bangladesh J Med Biochem, 2013; 6(2): 40-48.

12. Lamsal M,Gautam N, Bhatta N, Majhi S, et al. Diagnostic Utility of Adenosine Deaminase (ADA) Activity in Pleural Fluid and Serum of Tuberculous and Non-tuberculous Respiratory Disease Patients. In: Southeast Asian J Trop Med Public Health, 2007; 38 (2): 363-69.
13. Boonyagars L, Liertiburanakul S. Use of adenosine deaminase for the diagnosis of tuberculosis: a review. In: Journal of Infectious Disease and Antimicrobial Agents, 2010; 27: 111-8.

14. Urunsak IF, Gulec UK, Paydas S, Seydaoglu G, Guzel AB, Vardar MA. Adenosine deaminase activity in patients with ovarian neoplasms. In: Arch Gynecol Obstet, 2012; 286(1): 155-59.

15. Aghaei M. Diagnostic Value of Adenosine Deaminase Activity in Benign and Malignant Breast Tumors. In: Archives of Medical Research, 2010; 41(1): 14-18.

16. Nariman AH, Eissa SA, Masaoud HH, Elessawy. Diagnostic value of adenosine deaminase in tuberculous and malignant pleural effusion. In: Egyptian Journal of Chest Diseases and Tuberculosis, 2012; 61(4): 413-17. 